\title{
Capitalismo e razão neoliberal: ódio colonial e extermínio de travestis e transexuais no Brasil
}

\section{Capitalism and neoliberal reason: colonial hatred and extermination of transgenders in Brazil}

\author{
Carla Cristina Garcia ${ }^{a}$ \\ (1) https://orcid.org/0000-0002-5075-3129 \\ Fabio Mariano da Silva ${ }^{a}$ \\ (1) https://orcid.org/0000-0002-3429-2377 \\ Marcelo Hailer Sanchez ${ }^{a}$ \\ (D) https://orcid.org/0000-0003-1626-7319
}

Resumo: O presente artigo objetiva tratar sobre a forma como o ódio colonial vem sendo historicamente capitaneado pelo capitalismo, perpetuando, a partir do Estado moderno, uma estrutura racial e sexista que alijam pessoas negras, mulheres e LGBT. Ainda que interseccionada, iremos nos deter no ódio direcionado às pessoas transgêneros, sujeitos cujo controle da vida e dos corpos tem revelado ódio como projeto de Estado neoliberal que promove a invisibilidade e o extermínio dessas pessoas.

Palavras-chave: Capitalismo. Ódio. Travesti. Modernidade. LGBT.

\begin{abstract}
This article aims to deal with the way colonial hatred has been historically dominated by capitalism, perpetuating from the Modern State a racial and sexist structure that black people, women and LGBT. Although intersected, we will focus on hatred toward transgender people, subjects whose control of their lives and bodies has revealed Hatred as a neoliberal state project that promotes their invisibility and extermination.
\end{abstract}

Keywords: Capitalism. Hated. Transgender. Modernity. LGBT. 


\section{Introdução}

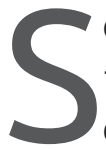

obre aquilo que é o ódio, o psicanalista Christian Dunker (2017) indica uma função transformadora para esse afeto, considerando-o como elemento de uma política de sentimentos necessária à vida das pessoas: "O ódio é um afeto importante" (p. 71).

Para o autor, os afetos têm uma recorrência, um locus de incidência, ocasião em que lembra o filósofo Sêneca, para quem o ódio é o afeto dos impotentes. Não vamos tratá-lo do ponto de vista da subjetividade individual, mas no campo das experiências políticas e, portanto, da sua localização a partir, mas não somente, do Estado.

As políticas neoliberais, em seu aspecto estrutural, estabelecem como premissa que aquele que desloca o ódio questiona a forma-de-vida, retirando a possibilidade de esses sujeitos viverem a sua emancipação política. Para Agamben apud Barbosa (2013), esse mecanismo incide na forma como o ser/sujeito estará fora dos laços de sujeição a todo tipo de soberania. Desse modo, esses sujeitos, ainda que retratados como bando, já que estão sob a mira da lei, são por ela abandonados. ${ }^{1}$

O ódio perpassa os sujeitos para que, a partir das suas diferenças, tenham retiradas as suas condições políticas de existência. A narrativa do ódio informa quem é o sujeito em relação àquele que fala, determinando a sua condição de vulnerabilizado. Temos aí um paradoxo: por meio da política de ódio, as dissidências se colocam em campo de disputa pela concessão de direitos de cidadania, ao mesmo tempo em que por meio do avanço das lutas sociais temos a consolidação da política de ódio como resposta.

Se a perspectiva do Estado e suas políticas demonstram em sua trajetória como se afirma em termos de narrativa, o ódio desloca-se para vários conjuntos sociais, entre eles lésbicas, gays, travestis e transexuais - LGBT2 ${ }^{2}$, pretos e pretas e mulheres, alvos do ódio insidioso do Estado:

1 O termo abandono, em sua origem, in bando, a bandono, significa, em italiano, à mercê de.

2 LGBT é a sigla que denomina de maneira universal como grupo identitário o conjunto de pessoas lésbicas, gays, travestis e transexuais. Quando acompanhada do símbolo “+”, indica outras dissidências. Neste artigo, utilizamos a sigla LGBT - no singular, de acordo com o que 
"A mera existência do outro é sentida como decréscimo de felicidade, um rapto de gozo ao sujeito, uma ofensa à sua forma de vida" (Dunker, 2017, p. 73).

Centraremos nos dados sobre a cultura do ódio direcionada à população de travestis e transexuais, cuja vida tem sido diuturnamente obstada de condições mínimas de cidadania, como resultado de um processo histórico que envolve o período de colonização da América e a construção da hierarquia de raças, a consolidação de classificações como normal e anormal, bem como a edificação do capitalismo enquanto modo de produção, mas que, além do capital, necessita do racismo e do ódio às diferenças para existir.

Este artigo parte de outras produções. A primeira delas do Programa Transcidadania, transformado em política pública pela gestão municipal da cidade de São Paulo nos anos 2012 a 2016. O segundo que resultou no livro $O$ rosa, o azul e as mil cores do arco-íris: gêneros, corpos e sexualidade na formação docente (org. Garcia, 2017). E o terceiro com os dados extraídos da tese de doutorado Políticas de morte para corpos sem lei: travestis e homens e mulheres transexuais - da invisibilidade da vida ao descaso na morte (Silva, 2019).

\section{As políticas colônias e a produção do ódio}

A predileção pela a eliminação das diferenças por meio do desenvolvimento de uma cultura do ódio tem um de seus pontos de partida identificáveis a partir de 1492, com a conquista da América e o paradigma fundante da organização racial do mundo.

Para Grosfoguel (2008), é a partir do mito da terra vacante que se começa a estabelecer o que é humano, o que é cultura, o que é progresso e, principalmente, o que é civilização. Desenvolve-se a ideia e o projeto

foi acordado em 2008 na I Conferência Nacional GLBT (à época). Disponível em: https://www. mdh.gov.br/informacao-ao-cidadao/participacao-social/old/cncd-lgbt/conferencias/anais-1a-conferencia-nacional-lgbt-2. Acesso em: 28 abr. 2019. 
político que ganha o nome de "Europa". As identidades serão utilizadas pelos países coloniais na decisão sobre quem deve viver e quem deve morrer.

A partir da teoria das raças, todo aquele que não fosse branco seria incluído na esfera das anormalidades e do não desejável. Essa narrativa ganha particular fortalecimento com a publicidade colonial inglesa a partir do século XVII (McClintock, 2010). É por meio dela que McClintock enxerga a racialização e a sexualização da mercadoria. Citando Marx, a autora observa como o sabão tornou-se uma mercadoria excepcionalmente lucrativa em meio às crises econômicas da época, como um produto tão representativo do espaço doméstico migrava para as colônias e as classes subalternas como símbolo de purificação racial - no cartaz do Pears' Soap (figura 1), o menino negro que se lava na banheira com o sabão se torna branco do pescoço para baixo - e como a África conquistada pelas mercadorias domésticas reafirmava sua feminilidade na retórica imperialista, consolidando a cultura europeia como o modelo de comportamento a ser seguido.

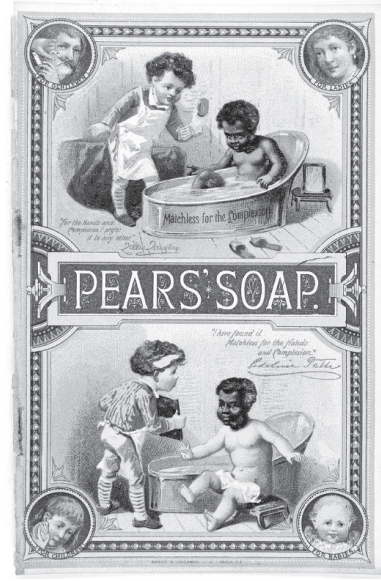

Figura 1. Advert for Pears' Soap.

Fonte. Wellcome Library, Londres. Direitos autorais: Copyright work available under Creative Commons Attribution only licence CC BY 4.0. Disponível em: http://creativecommons.org/licenses/by/4.0/

Para a autora, surge o que vai chamar de tempo panóptico e espaço anacrônico: no primeiro se dá a narrativa universal da história a partir de um ponto geográfico invisível, ou seja, pode ser de qualquer lugar, porém 
esse qualquer lugar é sempre a Europa; o espaço anacrônico funciona dentro do tempo panóptico e é ele que vai estabelecer os povos que se encontram no tempo moderno e aqueles que permanecem no arcaico, ou seja, não evoluíram. É também dentro da narrativa do espaço anacrônico que se dá a construção das sexualidades precárias.

Para McClintock (2010), é nesse tempo histórico que a languidez - característica socialmente identificada como feminina - passa a ser associada aos negros e aos nativos e adquire significados negativos, como traços de uma masculinidade fracassada, frente ao homem branco cuja masculinidade altiva e hegemônica o faz estar sempre olhando e caminhando para a frente.

A fundação da família nuclear possui uma relação intrínseca com a ojeriza para com tudo aquilo construído fora desse modelo. A autora associa essa questão a processos históricos mais amplos, a "cruzamentos perigosos" (McClintock, 2001, p. 161) entre classe e gênero situados nos meandros da sociedade capitalista. McClintock identifica, por exemplo, uma análise racializada no pensamento de Friedrich Engels (2008) sobre a situação da classe trabalhadora na Inglaterra. Considera que o filósofo "figura as crises familiares que assolam os pobres urbanos através da iconografia da raça e da degeneração" (McClintock, 2001, p. 76). Engels veria a condição da classe trabalhadora inglesa - degradada e degenerada - como se tratasse da condição de uma raça diferente, desprovida de humanidade, reduzida à bestialidade em razão da miséria a que a burguesia inglesa lhe obrigava.

Engels descobriu "a decadência universal da vida familiar entre os trabalhadores". De fato, a tragédia da universal "Família do Homem" da classe trabalhadora era que "a vida familiar [...] é quase impossível". Ademais, na visão de Engels, há uma causa para a confusão: "É inevitável que, se uma mulher casada trabalha numa fábrica, a vida familiar é inevitavelmente destruída". (McClintock, 2001, p. 76)

Tal reflexão, realizada por Engels, se alinharia àquilo que McClintock chama de "analogia triangular entre as degenerações racial, de classe e 
de gênero" (p. 76) e que consistiria numa forma especificamente moderna de dominação social.

Engels imagina as primeiras grandes crises do industrialismo através dos dois tropos da degeneração e da Família do Homem - um tropo extraído do reino da domesticidade e o outro, do reino do império. Testemunha-se aqui a figura de um duplo deslocamento: a história global é imaginada como uma família universal [...] enquanto as crises domésticas são imaginadas em termos raciais. [...] Por esses dois discursos dominantes: o tropo da degeneração (reversível como o tropo do progresso) e o tropo da Família do Homem. (McClintock, 2001, p. 76)

Na segunda metade do século XIX, a ideia de desvio racial se fazia empregar no policiamento vigilante das classes perigosas, ou seja, "a classe trabalhadora militante, os irlandeses, os judeus, as feministas, os gays e as lésbicas, as prostitutas, os criminosos, os alcoólatras e os loucos" (p. 77), todas vistas como atávicas em regressão a um momento primitivo da história humana. Essa analogia das degenerações é, então, costurada por McClintock ao tecido do projeto imperial. Uma dialética intricada entre a domesticação das colônias e a racialização da metrópole manejava uma noção metafórica de família através da qual a desistoricização das colônias e de suas terras - vistas como virgens, intocadas, quase pré-discursivas - enlaçava-se à historicização das elites coloniais, autoproclamadamente distintas do populacho sexual e racialmente contagioso.

A família ocidental como a conhecemos hoje, bem como a noção de diferença sexual ou a própria ideia de dois sexos biológicos distintos, é uma concepção que pode ser historicamente contextualizada em torno dos séculos XVIII e XIX (Laqueur, 2001). Segundo Foucault (1994), é no século XIX que a construção social em torno do sexo feminino ganha importância, em contraste com o século XVIII, quando se falava mais do sexo masculino. Até essa época, predominaria um modelo, herdado dos gregos, que admitia a existência de apenas um sexo biológico, enquanto o gênero se apresentaria em pelo menos duas possibilidades. 
O importante disso tudo é que haveria, então, um só corpo, para o qual se atribuiriam distintas marcas sociais ou inscrições culturais. Esse modelo teria prevalecido até o Renascimento, quando entrou em curso uma série de fatores que propiciaram a passagem para o modelo de dois sexos, baseado em uma biologia da incomensurabilidade. Laqueur (2001) destaca que as descobertas científicas só fazem sentido e só acontecem dentro de um contexto social propício e respondendo a demandas sociais particulares em cada momento. Neste sentido, pode-se dizer que, sob a perspectiva biológica, a raça, a sexualidade e o corpo foram produtos das grandes revoluções no mundo que inauguraram a modernidade.

Além disso, a partir da formação do Estado moderno e, por consequência, de suas instituições, a hierarquização das diferenças ocorreu de maneira a tratar, por meio das normas médicas e estatais, todas as dissidências no campo da patologia e da anormalidade, à medida que o degenerado, aquele que foge da compulsão burocrática institucional, se afasta da norma, se desvia do caminho do normal.

A partir da teoria da hierarquização das raças estabelecida pelo capitalismo na disseminação de seu projeto liberal é que se dá a implantação de uma pedagogia do ódio. Assim, ao não se reconhecer por um signo de sociabilidade, o homem tornava-se um animal não cognitivo. O homem animalizado durante a formação do Estado era tomado a partir de diferentes grupos em seus aspectos físicos e culturais, como demonstra Almeida (2018, p. 22): "A classificação de seres humanos serviria para consolidar um projeto de colonização europeia sobre povos de outros continentes". Para cientistas como Cornélius de Pauw, os indígenas americanos não tinham história, além de seres infelizes e degenerados (Almeida, 2018); para Hegel, os africanos seriam povos sem história, bestiais e envoltos de ferocidade: "O negro representa, como já foi dito, o homem natural, selvagem e indomável. [...] Neles, nada evoca a ideia de caráter humano (1995, p. 88).

Pode-se dizer que o ódio à diferença é a marca histórica das várias etapas do capitalismo que se utiliza de subsídios raciais, de gênero, de classe, por meio das suas instituições, que vão se reconfigurando à medida da complexidade social, pois, para que se estabeleça em qualquer 
território, é preciso que ele alcance o maior nível possível de homogeneidade. Não se trata de uma coincidência que os grupos historicamente perseguidos e difamados sejam quase sempre os mesmos em variadas partes do mundo. A elaboração e a expansão da mentalidade racista, bem como a eliminação da diferença — seja ela qual for — faz parte e é condição para a estruturação do capitalismo enquanto sistema-mundo (Wallerstein, 2004), que propõe a análise do capitalismo a partir de uma visão sistêmica, e não como um sistema constituído de partes isoladas. Uma das teses do autor estabelece que é o sistema capitalista, desde o século XVI, que impõe e organiza a pobreza nos países do chamado Terceiro Mundo.

Uma das consequências da colonização dos saberes (Lander, 2000) e a maneira como ela impôs um modelo único de civilização é a de que se trata de uma ação que não pode ser entendida fora do liberalismo, pois desde o seu surgimento o liberalismo foi imaginado não apenas como uma prática econômica, mas também como um modelo de organização da vida (Dardot; Laval, 2016). O liberalismo e a sua versão mais recente, o neoliberalismo, aplica uma "norma de vida" (Idem) que produz tipos de vida e formas de existência. O liberalismo não inaugurou apenas uma maneira de se pensar o mercado e as transações econômicas, criou uma razão no mundo.

Por isso essa razão é global nos dois sentidos do termo: é "mundial" no sentido de que vale de imediato para o mundo todo; e, longe de limitar-se à esfera econômica, tende à totalização, isto é, a "fazer o mundo" por seu poder de integração de todas as dimensões da existência humana. Razão do mundo, mas ao mesmo tempo uma "razão-mundo" (Dardot; Laval, 2016, p. 16).

Aceitar que o liberalismo e o capitalismo, além de se tornarem o sistema-mundo, são também a razão-mundo (Dardot; Laval, 2016) facilita a compreensão de como os saberes criados em torno desse sistema/ razão-mundo se ocuparam das mentes para além do território europeu.

As instituições incorporadas pelo sistema-mundo capitalista reiteram a maneira de perpetuar os mecanismos de continuada distribuição da 
morte pelo ódio à diferença — o racismo, como mecanismo de propagação do ódio, tem orientado narrativas no mundo todo: "O racista é a pessoa que se afirma pelo ódio, construindo o Outro. [...]como seu objeto ameaçador do qual seria necessário se proteger, se desfazer ou ao qual caberia simplesmente destruir [...]”. (Mbembe, 2018b, p. 12). Além disso, é necessário verificar a forma como outras instituições agem no que concerne à possibilidade de difusão de discursos e práticas de ódio. Foucault (1979, p. 80) nos alertava a respeito da formação de uma medicina na França: "O controle da sociedade sobre os indivíduos não se opera simplesmente pela consciência ou pela ideologia, mas começa no corpo, com o corpo".

Contribuindo com essa visão, raça, gênero e classe, oriundas de um sistema-mundo. produziram cânones que ecoaram sobretudo no Ocidente, e com mostras nos campos de extermínio. Para Esposito (2010, p. 163-164):

É conhecido o papel desempenhado pelos médicos nazis no extermínio praticado pelo regime [...] a participação directa em todas as fases do homicídio em massa: da escolha das crianças, e depois dos adultos destinados à morte misericordiosa do programa $\mathrm{T} 4$ até a extensão daquilo que se continuou chamar eutanásia aos prisioneiros de guerra, até a grandiosa Therapia magna auschwitziense, seleção na rampa de acesso ao campo, início do processo de gaseamento, declaração de óbito, extraç̧ão de dentes de ouro dos cadáveres...

Agamben (2010), ao refletir sobre dos campos de concentração como paradigmas das sociedades modernas, diz que esse é o local onde a narrativa do ódio se cristalizou sob a premissa do assujeitamento, da subordinação e muito fortemente da morte. As instituições sob o governo do soberano converteram o pensamento universal na ciência do policiamento, sob o forte apelo do nacional socialismo, como vem ocorrendo em vários países. ${ }^{3} \mathrm{~A}$ eugenia foi a forma que o ódio e a morte

3 Disponível em https://internacional.estadao.com.br/noticias/nytiw,onda-de-nacionalismo-hindu-divide-ainda-mais-a-india,70002796050. Acesso em: 20 abr. 2019. 
se manifestaram como projeto de Estado e que estipularam premissas para que as sociedades modernas adotassem tais ações

As colônias, os campos, são instituições que vêm operando de acordo com a narrativa da legalidade, por isso, o soberano, ao inferir a ordem para que se descumpra a ordem, não suspende o espectro normativo, mas o altera conforme seu entendimento, segundo o qual, sob essa justificativa, não agiu fora dela. Ao retirar o estatuto jurídico de negros, mulheres, LGBTT+, o soberano o faz por convicção de que a lei assim o autorizou a agir. (Silva, 2019, p.60)

A exceção como política implementada no Estado sob o viés da legalidade e tornada regra se configurou na escravidão a que foram submetidos os povos originários, nas plantations como descreve Mbembe (2018a), e na figura do muçulmano, aquele que não deve ser visto, mas, se o for, não deve ser lembrado, relegado à condição de inexistente nos campos de concentração de que trata Agamben (2008).

\section{Entre oceanos e atlânticos: tempo de paz, tempo de matar}

A partir do colonialismo, a mentalidade racista se assenta e se espalha por toda a América e passa a introduzir diferenças que antes não existiam entre os povos originários (Lugones, 2008). Neste sentido, pode-se dizer que o racismo é uma invenção do sistema capitalista (Williams, 2012) que se organiza dentro do sistema mundo de maneira a alcançar e influenciar todas as formas de vida. $\mathrm{O}$ capitalismo deu origem a outros sistemas de ódio, entre eles, o sexismo e o machismo.

Além do processo genocida perpetrado nos territórios colonizados pelos países do Norte Global, a introdução da hierarquia das raças e dos sexos vai ter um importante papel na desestabilização dos povos americanos e africanos. Líderes locais em alianças com homens brancos colonialistas articulam a retirada das mulheres dos locais de poderes. Essa 
articulação entre o patriarcado colonial e o patriarcado interno acarretará danos irreparáveis a vários povos dos dois continentes (Lugones, 2014).

McClintock (2010) analisa que com o auge da Revolução Industrial ocorrerão as migrações em massa do campo para as cidades e estas começarão a ter um novo desenho a partir da coexistência das diferenças: religiosas, culturais e sexuais. $O$ cenário homogêneo vai aos poucos deixando de existir e as diferenças de classe se aprofundam. Na medida em que as colonizações avançavam na América e em partes do continente africano, uma mentalidade com base na hierarquia racial e sexual também ganhava o mundo ao atravessar oceanos e atlânticos.

A consolidação do modo de produção capitalista dentro e a partir das colonizações por si só não é suficiente para que possamos compreender os motivos que levam a política de ódio a permanecer incrustada nas sociedades ocidentais, até porque, ao mesmo tempo em que se desenvolveram, as nações capitalistas investiram na disseminação de narrativas universais sobre o mundo de maneira a reinterpretá-lo constantemente.

Uma das tecnologias utilizadas é o entendimento e o convencimento de que países da América Latina e do continente africano sejam compreendidos no âmbito do espaço anacrônico (McClintock, 2010), ou seja, como nações e culturas atrasadas, selvagens e menos humanas, para que o extermínio dessas culturas nunca fosse condenado na história. É nesse processo cultural que o ódio vai se tornar algo naturalizado quando direcionado a determinadas populações.

Essa narrativa conta com aliados e mecanismos para complexificar e justificar os crimes de ódio. Dois deles merecem destaque para que se possa entender - ainda que parcialmente - o ódio presente no Ocidente nesse começo de século XXI: o primeiro se dá pela produção de saberes sobre esses outros povos que serão enquadrados na categoria do exótico (Said, 2003); o segundo, pela disseminação da razão liberal, que vai, a partir do século XIX, dar início à construção daquilo que Dardot e Laval (2016) chamam de "o homem empresarial". Juntamente com a exotificação dos povos e culturas não brancas há essa mentalidade extremamente 
individualista que vai sendo arregimentada na contramão das agendas, seja socialista, seja social-democrata.

Os autores, ao fazerem uma genealogia do neoliberalismo, demonstram, por um lado, que ele não é uma simples continuidade do liberalismo clássico do século XVIII, do mesmo modo que não é seu extravio nem sua negação; por outro lado, para problematizá-lo a partir de suas vertentes e disputas internas, mostram como ele passou de uma doutrina econômica para um "sistema normativo que ampliou sua influência ao mundo inteiro, estendendo a lógica do capital a todas as relações sociais e a todas as esferas da vida" (p. 7)

Mas, qual é a relação do homem empresarial com a persistência do ódio? O ódio de classe e o ódio sexista. Como vimos, toda a masculinidade não viril será tratada como algo anormal e associado aos povos não brancos e que a família nuclear será o centro nerval do capitalismo a partir do século XVIII, ou seja, a união familiar-nuclear reprodutora e branca. Uma forma de entender como esse homem viril foi se formando no contexto de uma sexualidade compulsória se dá a partir da formação dos Estados e suas revoluções, mas sobretudo com a invenção dos espaços públicos e privados destinados a homens e mulheres em separado e que foram fundantes para que a biologia se instaurasse como determinante nos estereótipos a partir do sexo e da raça.

Essa estrutura racista, machista, misógina e heteroterrorista ${ }^{4}$ se mantém intacta nos países do Ocidente. $O$ fato de que a mentalidade ocidental ainda esteja toda estruturada na exotificação e eliminação dos corpos não brancos e não heterossexuais - mesmo naqueles países que passaram por governos de cunho socialista ou progressista (ainda que, nesse caso, tenham sido liberais) não conseguiram dar uma resposta

4 Utilizaremos heteroterrorismo em detrimento de homofobia, considerando que Ritxar Bacete (2017) nos alerta para o fato que o machismo e terrorismo têm elementos em comum, entre eles: a legitimação da violência, o ataque a direitos fundamentais, a dominação dos sujeitos sociais sobre os outros por sua condição de gênero e/ou sexualidade. Consideramos necessária a qualificação da violência, sob o risco de criar novas patologias que encubram crimes de ódio. 
eficaz aos crimes de ódio já que se pautam por valores e modelos colonialistas, ou seja, racistas.

Se por um lado o sistema normativo operado pelo neoliberalismo possui, em sua raiz, uma ojeriza pelas diferenças, e neste caso nos referimos às sexualidades e corpos dissidentes, ao mesmo tempo o sistema capitalista assimila uma parcela dos corpos indesejáveis. Se não há como escondê-los, que sejam higienizados e alocados no quadro normativo familiar (Foucault, 1988).

\section{A estrutura do ódio: travestis e transexuais no Brasil}

Ainda que muitos países venham adotando políticas de reconhecimento das identidades trans, de maneira a desestimular políticas de ódio - como no caso da Suécia que, em 1 de janeiro de 2019, passou a reconhecer a paternidade trans ${ }^{5}$ como exigência da Assembleia Parlamentar do Conselho da Europa -, nações como Brasil, a partir da eleição de Jair Bolsonaro à Presidência da República, vêm calcando seu discurso em livrar o país do comunismo e da ideologia de gênero - com foco na defesa da família, que, segundo seu discurso, estava ameaçada de extinção. Essas afirmações nos colocam em um profundo paradoxo que, até o momento, não foi discutido: como o país que realiza a maior Parada LGBT ${ }^{6}$ do mundo e que tem metade de sua população constituída por pessoas negras elegeu um presidente da República com histórico de declarações homofóbicas e racistas?

Observa-se que uma série de direitos tem sido produzidos em relação à comunidade LGBT, especialmente para travestis, mulheres transexuais

5 Disponível em: https://tgeu.org/sweden-recognises-trans-parenthood/. Acesso em: 27 abr. 2019.

6 A edição de 2007 do Guinness Book registrou a Parada LGBT de 2006 como a maior do mundo. A Polícia Militar do Estado de São Paulo não fornece mais o número de participantes. O recorde obtido pelo parada paulista foi retirado das edições seguintes do Guinness Book. Todavia, a Parada LGBT de São Paulo ainda é considerada o maior evento público do mundo destinado aos LGBT. 
e homens trans. Esse conjunto, repercute, grosso modo, direitos básicos, como a retificação do prenome e do sexo nos documentos civis oficiais, independente da cirurgia de transgenitalização. Essa decisão foi embasada pelo Supremo Tribunal Federal por meio de demanda formulada em 2009 pela Associação Nacional de Travestis e Transexuais (Antra) à Procuradoria Geral da República (PGR). A Ação Direta de Inconstitucionalidade - ADI 4275 - 1/600 tramitou e, em 9 de março de 2018, o STF decidiu pelo reconhecimento do pedido.

Outras normativas também ampararam esse conjunto social, em especial em órgãos públicos que passaram a adotar, independente da formulação de pedido junto ao Judiciário, o nome social como fator de reconhecimento da identidade de gênero dessas pessoas. Universidades, órgãos do Sistema Único de Saúde - SUS, organismos do governo, assumiram como premissa o respeito à identidade de gênero e sexualidades como conduta das relações que se estabeleciam. De fato, isso garantiu que parte da angústia fosse sanada ou atenuada pelos(as) usuários(as) e profissionais que iam se inserindo no campo profissional formal nesses organismos.

No entanto, é preciso pensar que a despeito das medidas esparsas que vão reorientando travestis, mulheres transexuais e homens trans, outras medidas são necessárias para que haja uma resposta ao discurso de ódio contra corpos e sexualidades dissidentes. Isso porque efetivamente os(as) integrantes desse grupo continuam sendo sistematicamente convertidos(as) em números estatísticos de morte ao serem expulsos(as) de suas casas por volta dos treze anos ${ }^{7}$ e nunca voltam em razão da não aceitação da família ou de seu meio social. Além disso, morrem precocemente, como apontam os números abaixo, numa média de 35 anos de idade, quando dados do Instituto Brasileiro de Geografia e Estatística — IBGE estipula que idade média de brasileiros(as) é de 75,8 anos. ${ }^{8}$

7 Disponível em: https://observatorio3setor.org.br/noticias/expectativa-de-vida-de-transexuais-e-travestis-no-brasil-e-de-35-anos/. Acesso em: 27 abr. 2019.

8 Disponível em: https://agenciadenoticias.ibge.gov.br/agencia-noticias/2012-agencia-de-noticias/noticias/18469-expectativa-de-vida-do-brasileiro-sobe-para-75-8-anos. Acesso em: 20 abr. 2019. 
A vítima mais jovem noticiada tinha 16 anos e a mais velha 53 anos. O Mapa aponta que 67,9\% das vítimas tinham entre 16 e 29 anos, caindo para $23 \%$ aquelas entre 30 e 39 anos, 7,3\% entre 40 e 49 anos, e para 1,8\% acima dos 50 anos. Nota-se que os índices mais altos de assassinato da população trans, está diretamente relacionado as questões etárias. Onde quanto mais jovem, mais suscetíveis à violência e à mortandade. Ao contrário daquelas pessoas que ultrapassam a estimativa de vida, veem a possibilidade de ser assassinada/o diminuir ao longo de suas vidas. (Benevides, 2017, p. 17)

Em 2018, uma série de relatórios produzidos por organismos da sociedade civil denunciava a forma como LGBT, mulheres e pessoas negras, em especial jovens, vinham morrendo. Esses dados acompanhados evidenciam o resultado do discurso de ódio praticado no campo da política, à medida que, em vez de potencializar sujeitos, visa unicamente o seu extermínio por meio da economia de direitos, da precarização das condições de vida, da produção da morte.

Mapas da violência têm sido produzidos como forma de denúncia de um conjunto de (in)ações estatais que, decorrentes do ódio, produzem a violência e a morte, apontando o Brasil como um dos países que mais matam LGBT em relação ao mundo, incluindo países onde gêneros e sexualidades dissidentes são criminalizadas, conforme aponta a Transgender Europe — TGEU em seu relatório anual. ${ }^{9}$ A Associação Nacional de Travestis e Transexuais - Antra ${ }^{10}$ tem atuado no combate efetivo contra as constantes violações de direitos desse grupo, ao produzir dados da violência cometida.

No ano de 2017 ocorreram 179 assassinatos de pessoas trans, das quais 169 eram travestis e mulheres transexuais e dez eram homens trans. Os relatórios apontam que apenas dezoito casos tiveram os suspeitos presos, o que representa 10\% (Antra, 2017). No ano de 2018 ocorreram 163 assassinatos de pessoas trans, das quais 158 travestis e

9 O relatório de monitoramento aponta dados de violências contra pessoas transgêneros no mundo todo. Disponivel em: https://transrespect.org/wp-content/uploads/2018/11/TvT_TMM_ TDoR2018_Namelist_EN.pdf. Acesso em: 27 abr. 2019

10 A missão da entidade encontra-se disponível em: https://antrabrasil.org. Aceo em: 20 abr. 2019. 
mulheres transexuais, quatro homens trans e uma pessoa não binária. Destes, encontramos notícias de que apenas quinze casos tiveram os suspeitos presos, o que representa 9\% dos casos (Antra, 2018). ${ }^{11} \mathrm{Em} \mathrm{2019,}$ as mortes continuam ocorrendo, de forma que até a data de 1/11/2019 houve 103 assassinatos (Antra, 2019). ${ }^{12}$

Figura 2. Imagem do mapa divulgado pela Antra, relativo ao extermínio ocorrido durante o ano de 2018, por regiões

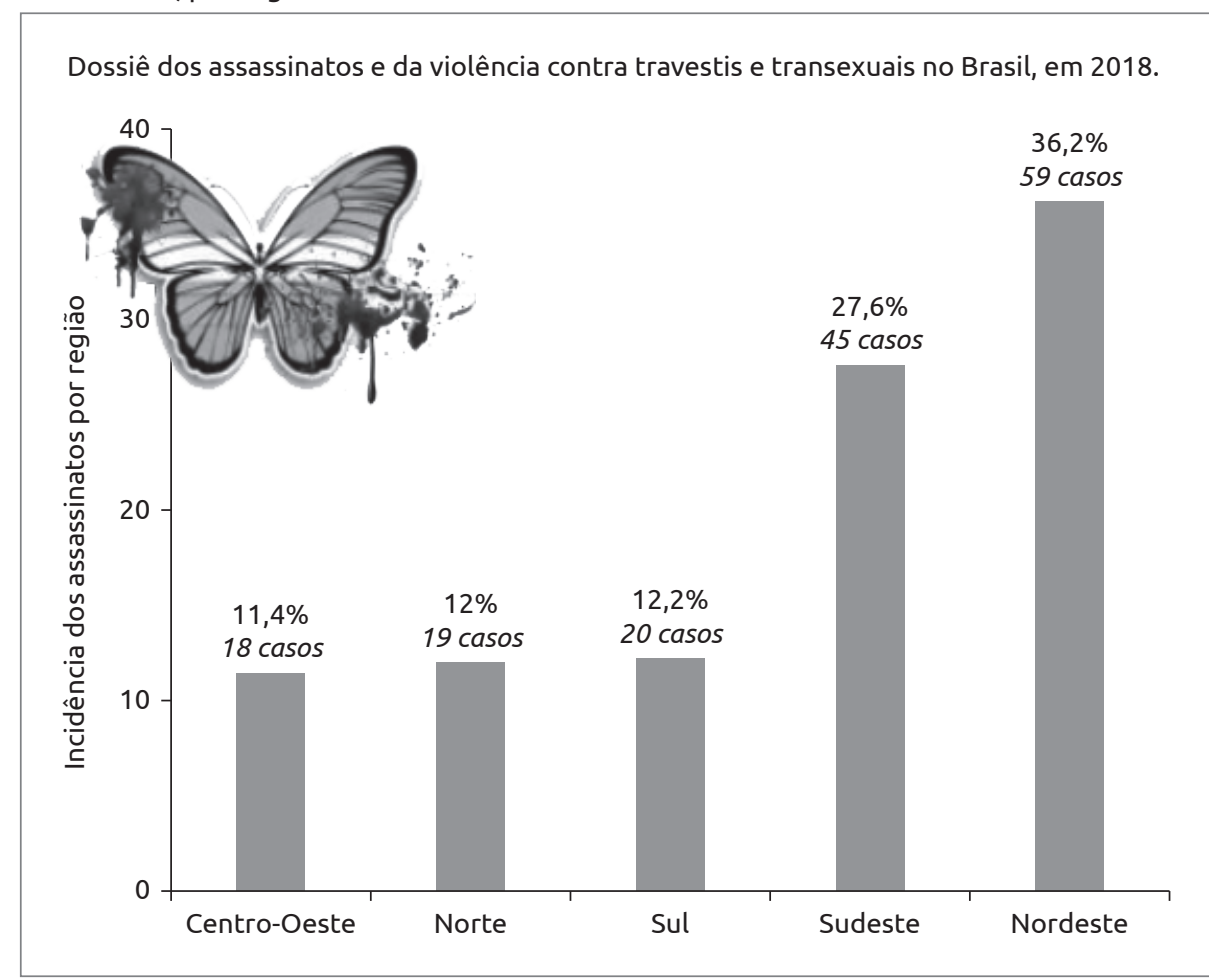

Fonte: Disponível em: https://antrabrasil.files.wordpress.com/2019/01/dossie-dos-assassinatos-e-violenciacontra-pessoas-trans-em-2018.pdf. Acesso em: 20 abr. 2019.

11 Dossiê divulgado pela Antra. Disponível em: https://antrabrasil.files.wordpress. com/2019/01/dossie-dos-assassinatos-e-violencia-contra-pessoas-trans-em-2018.pdf. Acesso em: 27 abr. 2019.

12 Mapa da Violência. Disponível em: https://antrabrasil.org/mapadosassassinatos/. Acesso em: 12 nov. 2019. 
Destaca-se o fato de que os crimes, em sua maioria, são originados por violência e crueldade de maneira extrema, sendo que armas de fogo, $53 \%$, lideram a forma como travestis e transexuais morrem no Brasil. O Dossiê 2018 apresenta ainda o fato de que 82\% dos casos foram identificadas como pessoas negras e pardas, ratificando o triste dado dos assassinatos da juventude negra no Brasil (Antra, p. 20), de maneira que essa população ainda enfrenta forte resistência em relação ao mercado de trabalho formal. Todos esses recortes nos indicam a incidência de aspectos que, interseccionados, apontam para uma política de extermínio.

Outro dado importante é que em razão da ausência de tipo penal específico, os casos são subnotificados e considerados como homicídio comum, quando na verdade há recorte de gênero, raça e classe envolvidos, sendo que muitas vezes esses dados são ignorados no momento da queixa. Por invisíveis que devem ser aos olhos do Estado, esses dados sequer são elaborados ou implantados, de maneira que não revelam o tamanho da omissão governamental.

No entanto, os dados apresentados pelo dossiê ${ }^{13}$ tratam de confirmar o fato de que no Brasil, de acordo com organismos nacionais e internacionais, são representados comparativamente da seguinte forma: 167 pessoas assassinadas no país em 2018, contra 71 no México, 28 nos EUA e 21 na Colômbia. De maneira que o Brasil concentra 41\% dos homicídios de pessoas trans no mundo.

\section{Considerações finais}

Como vimos, os dados apresentados são oriundos de um conjunto de ações e narrativas que tem no ódio uma postura civilizacional, implantada historicamente e perpetuada sob a guarida do capital. $O$ outro, neste caso travestis, mulheres transexuais e homens trans, ao representar a

13 Disponível em: https://antrabrasil.files.wordpress.com/2019/01/dossie-dos-assassinatos-e-violencia-contra-pessoas-trans-em-2018.pdf. Acesso em: 20 abr. 2019. 
abjeção, aquilo que não queremos ter por perto, tem sobre si o resultado imediato das políticas neoliberais. $O$ longo caminho que percorrem faz com que, ao buscarem direitos, acabem por se deparar com a contenção de direitos e a minimização da vida, a expulsão de casa, a humilhação burocrática, além da morte prematura como destino.

Poderíamos ainda, a partir desses dados, concordar com a tese de Michelle Alexander (2016) ao tratar da questão dos direitos civis nos Estados Unidos e questionar o fato de que, apesar dos avanços em relação aos direitos civis, o genocídio da população negra continuava a acontecer sob a presidência de Barack Obama, o que denominou como suborno racial. Portanto, tendemos a considerar, a partir do que vem ocorrendo no Brasil, que o Estado, ao escamotear dados e estabelecer narrativas do ódio, verificadas especialmente desde o processo eleitoral de 2018 , em relação ao conjunto social de travestis, mulheres transexuais e homens trans, pratica, por analogia, o que denominamos neste caso como suborno social (Silva, 2019).

O discurso da cordialidade é revestido de uma postura que nega a diferença e visa homogeneizar o sujeito, de maneira que ao ser evidente a dissidência de gênero e de sexualidade, outros percursos são traçados para a inexistência dessas vidas que são capturadas pelos instrumentos de poder e controle e exercem - a mando da razão liberal — um trabalho de controle sistemático da vida e da morte. Ao falar de Auschwitz, Sofsky apud Agamben (2008) lembra do trabalho sistemático de submissão daqueles que estão nos "campos" de extermínio à degradação física, moral, psicológica. Tornar corpos sem lei, para que o Estado aplique a sentença de morte por meio do ódio, esse é o papel que o Estado tem acentuado em suas narrativas políticas, sociais e econômicas.

No conjunto, o Estado e suas instituições, a partir de um projeto político neoliberal que elege as diferenças verificadas quanto a gênero e raça, criam mecanismos de divisão social que repercutem do ponto de vista da materialidade cotidiana na falta de empregabilidade pelos meios formais, de acesso a tratamentos médicos condignos para as especificidades de travestis, mulheres transexuais e homens trans, na 
dificuldade de ascensão escolar e educacional, reverberando, por conseguinte, na impossibilidade de emancipação e potencialidade dentro dos espaços de sociabilidade.

São os mecanismos de poder em pleno exercício e ação que aprofundam as narrativas do ódio e se inserem na estrutura de maneira a permanecer naturalizadas e normalizadas e que são, por isso, dificilmente assimiladas, a não ser por quem sofre.

É preciso, no entanto, em postura diametralmente oposta à pedagogia do capital instaladora do ódio, desde a Idade Média e perpetuada com a Modernidade, que seja possível a instalação de uma postura crítica e libertadora dos sujeitos em relação aos cânones coloniais, a qual, com o pensamento de Paulo Freire, ganhou repercussão internacional ao ser questionado o papel de formação dos sujeitos "Educação para homem-objeto ou educação para homem-sujeito [...]. Autorreflexão que as levará ao aprofundamento consequente de sua tomada de consciência e de que resultará sua inserção na História, não mais como espectadoras, mas como figurantes e autoras" (1983, p. 36).

Dessa forma, essa emancipação dos sujeitos deve se deslocar para o questionamento das estruturas econômicas, políticas e sociais, rechaçando discursos meramente retóricos que invisibilizam e recusam as mudanças nas causas estruturais, criminalizando e vitimizando sujeitos de direitos (Silva, 2019), adotando, como nos ensina Antígona, a premissa: “Não fui feita para conviver com o ódio" (Glucksmann, 2007, p. 30).

\section{Referências}

AGAMBEN, Giorgio. O que resta de Auschwitz: o arquivo e a testemunha (Homo Sacer III). Tradução: Selvino J. Assman. 1. ed. São Paulo: Boitempo, 2008.

AGAMBEN, Giorgio. Homo sacer: o poder soberano e a vida nua I. Tradução: Henrique Burigo. 2. ed. Belo Horizonte: Editora UFMG, 2010. 197 p.

ALEXANDER, Michelle. A nova segregação: racismo e encarceramento em massa. São Paulo: Boitempo, 2018. 
ALMEIDA, Silvio Luiz de. O que é racismo estrutural? Belo Horizonte: Letramento, 2018. ASSOCIAÇÃO NACIONAL DE TRAVESTIS E TRANSEXUAIS - Antra. Mapa dos Assassinatos de Travestis e Transexuais em 2017. Brasil, 2018.

BACETE, Ritxar. Nuevos hombres buenos, la masculinidad en la era del feminismo. 3. ed. Barcelona: Ediciones Península, 2018

BARBOSA, Jonefer. F. Formas-de-vida. In: Revista Hypnos. São Paulo, n. 30, p. 79-97, 1. sem. 2013.

BENEVIDES, Bruna; NOGUEIRA, Sayonara Naider Bonfim. Assassinatos e violência contra travestis e transexuais no Brasil em 2018. Disponível em: https://antrabrasil. files.wordpress.com/2019/01/dossie-dos-assassinatos-e-violencia-contra-pessoas-transem-2018.pdf>. Acesso em: 20 abr. 2019.

DUNKER, Christian. Reinvenção da intimidade: políticas do sofrimento cotidiano. São Paulo: Ubu Editora, 2017. 320 p.

ENGELS, Friedrich. A situação da classe trabalhadora na Inglaterra. São Paulo: Boitempo, 2008.

ESPOSITO, Roberto. Bios: biopolítica e filosofia. Tradução: M. Freitas da Costa. 1. ed. Portugal: Edições 70, 2010.

MBEMBE, Achille. Crítica da razão negra. Tradução: Sebastião Nascimento. São Paulo: N-1 Edições, 2018a. 320 p.

MBEMBE, Achille. O fardo da raça. São Paulo: N-1 Edições, 2018b. 30 p.

DARDOT, Pierre; LAVAL, Christian. A nova razão do mundo: ensaio sobre a sociedade neoliberal. São Paulo: Boitempo, 2016.

FOUCAULT, Michel. Microfísica do poder. Organização e tradução: Roberto Machado. Rio de Janeiro: Edições Graal, 1979.

FREIRE, Paulo. A educação como prática da liberdade. 14. ed. Rio de Janeiro: Paz e Terra, 1983.

GLUCKSMANN, André. O discurso de ódio. Tradução: Edgard de Assis Carvalho, Mariza Perassi Bosco. Rio de Janeiro: Difel, 2008. 272 p.

GROSFOGUEL, Ramón. Para descolonizar os estudos de economia política e os estudos pós-coloniais: transmodernidade, pensamento de fronteira e colonialidade global. Revista Crítica de Ciências Sociais, Coimbra, n. 80, p. 115-147, mar. 2008.

HEGEL, G. W. F. Filosofia da história. Brasília: Ed. UnB, 1995. 
LANDER, Edgardo. La colonialidad del saber: eurocentrismo y ciencias sociales. Perspectivas latinoamericanas. Buenos Aires: Clacso, 2000.

LAQUEUR, Thomas. Inventando o sexo dos gregos a Freud. Rio de Janeiro: Relume Dumará, 2001.

LUGONES, María. Rumo a um feminismo descolonial. Revista Estudos Feministas, Florianópolis, v. 22, n. 3, 2014.

MCCLINTOCK, Anne. Couro imperial: raça, gênero e sexualidade no embate colonial. Campinas: Editora da Unicamp, 2010.

SAID, Edward W. Orientalismo: o Oriente como invenção do Ocidente. São Paulo: Companhia das Letras, 2007.

SILVA, Fabio Mariano da. Políticas de morte para corpos sem lei: travestis e homens e mulheres transexuais - da invisibilidade na vida ao descaso na morte. 2019. Tese (Doutorado). Programa de Estudos Pós-Graduados em Ciências Sociais. PUC, São Paulo, 2019.

WALLERSTEIN, Immanuel Maurice. World-systems analysis: An introduction. [S.l.]: Duke University Press, 2004.

WILLIAMS, Eric. Capitalismo e escravidão. São Paulo: Companhia das Letras, 2012.

\section{Sobre os autores}

Carla Cristina Garcia - Doutora em Ciências Sociais.

E-mail: ca-cris@uol.com.br

FABIo MARIANo dA SiLVA - Doutor em Ciências Sociais.

E-mail: fama06@gmail.com

Marcelo Hailer Sanchez - Doutor em Ciências Sociais.

E-mail: marcelo.hailer@gmail.com 